\title{
Sclerosing epithelioid fibrosarcoma metastasizing to the penile shaft
}

\author{
Michael D. Bell, MD; Fadi Brimo, $M D ;{ }^{2}$ Sungmi Jung, $M D ;{ }^{2}$ Armen G. Aprikian, $M D^{\prime}$ \\ 'Department of Surgery, Division of Urology, McGill University Health Centre, Montreal, QC, Canada; ${ }^{2}$ Department of Pathology, McGill University Health Centre, Montreal, QC, Canada
}

Cite as: Can Urol Assoc J 2016;10(11-12):E398-400. http://dx.doi.org/10.5489/cuai.3528 Published online November 10, 2016.

\section{Abstract}

We present the case of a 50-year-old man with a periurethral mass. He was previously known for sclerosing epithelioid fibrosarcoma (SEF) of the left foot, having an amputation for local recurrence with $>2 \mathrm{~cm}$ negative margins. A solid periurethral mass was surgically excised seven months later, yielding the diagnosis of metastatic SEF. This is the first documented metastasis of SEF to the penis. These sarcomas have proven difficult to treat, with high recurrence rates despite a multimodal approach.

\section{Case report}

A 50-year-old non-smoking man of Chinese descent with a four-year history of left foot pain and swelling presented to an orthopedic clinic. He had no past medical history and was not taking medications. He had two prior excisional biopsies of a left forefoot lesion in another centre, yielding a presumably benign tumour followed by SEF. He was now being assessed for the recurrence of his foot pain two years from the last biopsy. Magnetic resonance imaging (MRI) demonstrated tumour at the previous surgical site. Computed tomography (CT) of the chest revealed multiple nodules up to $6 \mathrm{~mm}$. positron emission tomography (PET) scan was not suggestive of pulmonary metastases, however, increased uptake was seen in the prostate.

Radiotherapy directed at the foot was recommended prior to amputation in order to restage the pulmonary nodules in the event of metastases. The patient declined and opted for immediate amputation of the left forefoot with a curative intent. Histological examination of the predominantly subcutaneous/suprafascial $1.2 \mathrm{~cm}$ tumour revealed nests and cords of small, monotonous, round epithelioid neoplastic cells embedded in a prominent hyalinised sclerotic stroma, compatible with a diagnosis of SEF (Figs 1A, B, C). Surgical margins were negative and no lymphovascular invasion was identified. Failing an attempted biopsy of his small pulmon- ary nodules, he was concurrently referred to urology for the incidental PET finding.

At the time of urological assessment, the patient volunteered a three-month history of a nodule at the base of his penis. He was not experiencing any lower urinary tract symptoms or hematuria. On digital rectal exam his prostate was $60 \mathrm{~g}$, with no nodules or induration. His prostatespecific antiigen (PSA) was 1.41 and creatinine 70 umol/L. A mobile, non-tender, well-circumscribed, $1 \mathrm{~cm}$ lesion could be palpated on the ventral aspect of the proximal shaft. Cystoscopy demonstrated no involvement of the urethra and an otherwise normal examination. Interval scans of the chest revealed an increased size of his pulmonary nodules from initial staging, however, they remained subcentimetric and two consecutive scans had shown no interval growth. Initiation of chemotherapy continued to be deferred, as metastases could not be confirmed. He was booked for excision of his penile/scrotal mass.

At the time of the procedure, the mass remained freely mobile and did not appear to be tethered to the urethra on physical examination. Dissection demonstrated gross involvement of the corpus spongiosum. As margins would require resection of the urethra, the white fibrous-appearing nodule was dissected, taking a narrow margin involving corpus spongiosum. Pathological examination revealed histological features identical to the surgical specimen from amputation of the left forefoot (Fig. 1D). This confirmed metastastic SEF.

\section{Discussion}

SEF is a rare fibrosarcoma originally described in 1995. Meis-Kindblom et al published a case series of 25 patients having a well-circumscribed lesion with focal invasion into surrounding tissues. Primary lesions often originated in the lower extremities and limb girdles, trunk, upper limb girdles, and neck. The tumour grows as nests, strands, and cords of cells with scant cytoplasm, typically surrounded by collagenized stroma. Alveolar and acinar architectures have also been reported. With a low mitotic rate and bland histologic 


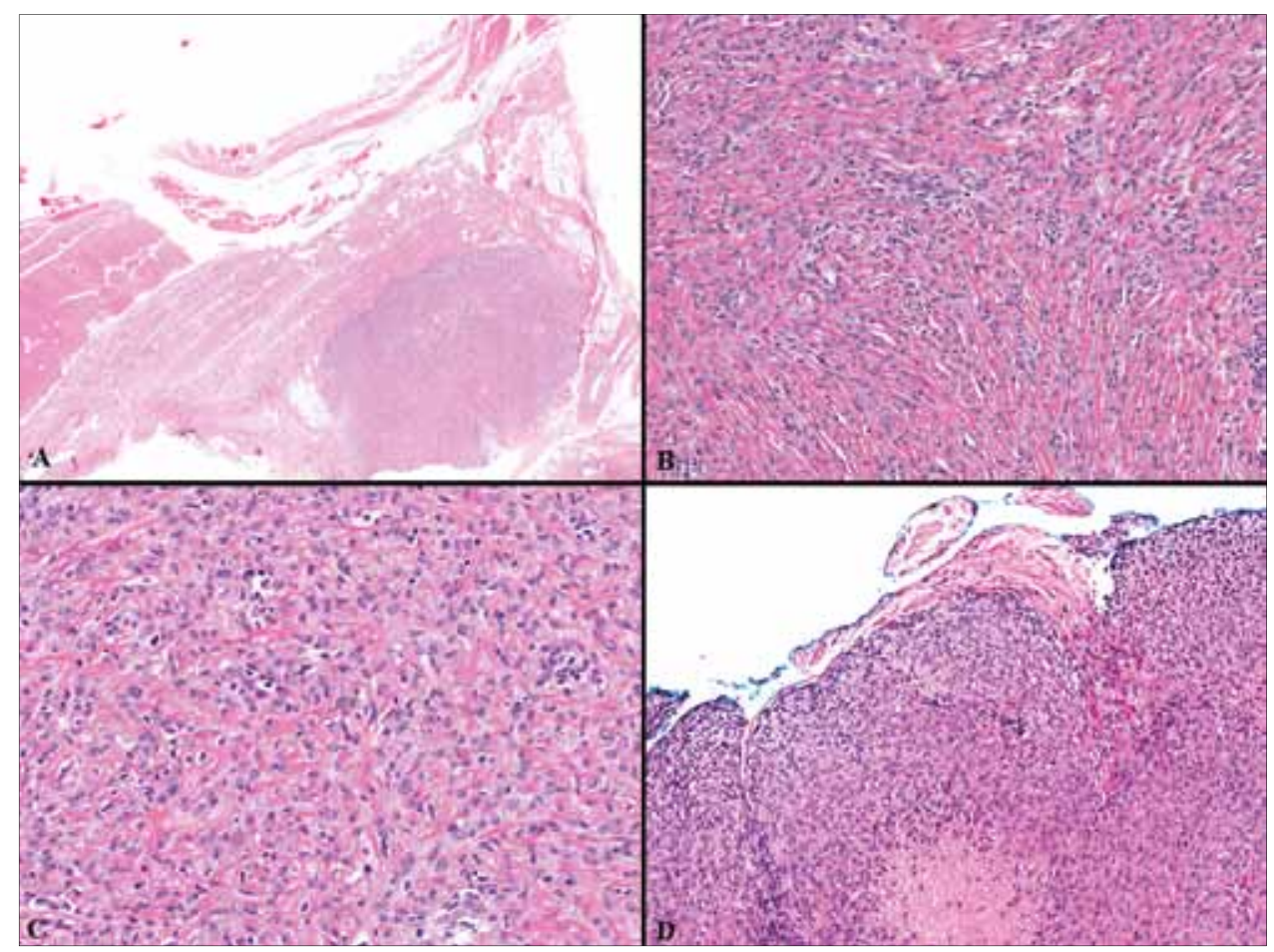

Fig 1. (A) Low-power view of the lesion in the foot showing a well-circumscribed suprafascial neoplastic nodule; $(\boldsymbol{B})$ the neoplastic cells grow in cords and as single cells and are separated by a heavily sclerotic stroma; (C) the cells are round, monotonous with mild degree of nuclear atypia; (D) the penile lesion showing identical morphology with extension to the inked peripheral surgical margin.

areas, it can be mistakenly classified as benign. ${ }^{1}$ Other primary sites have been described in the literature, including the pituitary gland, oral cavity, lung, bone, intra-abdominal, liver, pancreas, cecum, ovary, penis, and neuraxis. ${ }^{2-13}$

Despite being histologically low-grade, SEF has a high local recurrence rate. Originally reported as a rate of $53 \%$ at a median followup of 4.8 years, variable rates $(30-50 \%)$ have been described due to inconsistent reporting of followup. ${ }^{1-3}$ Distant metastases are most commonly reported to the lungs, with other sites including pleura and/or chest wall, kidney, stomach, bone, brain, pericardium, and lymph nodes. ${ }^{1,3,13,14}$ Rates of metastases were originally reported as $43 \%$ with a median followup of 7.7 years. ${ }^{1}$ Since then, rates of up to $86 \%$ have been published with a minimum of one year followup. ${ }^{2}$ One large systematic review of 90 patients revealed $83 \%$ had distant disease at a mean of three years post-diagnosis. In 67 patients with a mean followup of 3.8 years, $34 \%$ died from their disease, 35\% were alive with disease, and $31 \%$ were disease-free. ${ }^{3}$ Furthermore, metastases have been reported at a delay of up to 10 years. ${ }^{14}$

Treatment of this tumour has not been standardized, with various combinations of surgical techniques, chemotherapy, and radiotherapy being reported. Due to the rarity of the disease and inconsistent reporting of both treatment techniques and followup, the ideal therapy is yet to be determined, with some showing no effect of radiation and chemotherapy. ${ }^{1-4}$
We describe in this case a SEF presenting in the typical manner, mistaken as a benign lesion, and recurring at the site of primary excision. Along with this recurrence are suspicious subcentimetric pulmonary nodules, a common site of metastases, and a confirmed periurethral metastasis. This is, to the best of our knowledge, the first reported case of metastasis involving the corpus spongiosum and highlights the variable presentation and metastatic pattern of SEF. Two prior cases have been described of patients presenting with genitourinary symptoms. One case of a primary SEF at the base of the penis, and the second, a patient presenting with obstructive lower urinary tract symptoms found to have a large intra-abdominal mass displacing the bladder superiorly. ${ }^{2,11}$

\section{Conclusion}

Albeit rare, SEF has a large variety of presentations due to the diversity in primary and metastatic sites. Despite the 20 years since its discovery, SEF remains a challenge to treat and would, therefore, benefit from tumour board consultation to develop individual treatment strategies.

Competing interests: Dr. Aprikian has received grants/honoraria from AbbVie, Amgen, Astellas, and Janssen; and has participated in clinical trials for Astellas. The remaining authors report no competing personal or financial interests. 
Bell et al.

This paper has been peer-reviewed.

\section{References}

1. Meis-Kindblom JM, Kindblom LG, Enzinger FM. Sclerosing epithelioid fibrosarcoma: A variant of fibrosarcoma simulating carcinoma. Am J Surg Pathol 1995; 19:979-93. http://dx.doi.org/10.1097/00000478199509000-00001

2. Antonescu CR, Rosenblum MK, Pereira $P$, et al. Sclerosing epithelioid fibrosarcoma: A study of 16 cases and confirmation of a clinicopathologically distinct tumour. Am I Surg Pathol 2001; 25:699-709. http:// dx.doi.org/10.1097/00000478-200106000-00001

3. Ossendorf C, Studer GM, Bode B, et al. Sclerosing epithelioid fibrosarcoma: Case presentation and a systematic review. Clin Orthop Relat Res 2008;466:1485-91. http://dx.doi.org/10.1007/s11999. 008-0205-8

4. Bilsky MH, Schefler AC, Sandberg DI, et al. Sclerosing epithelioid fibrosarcomas involving the neuraxis: Report of three cases. Neurosurgery 2000;47:956-9. http://dx.doi.org/10.1097/00006123200010000-00031

5. Grunewald $T G$, von Leuttichau I, Weirich $G$, et al. Sclerosing epithelioid fibrosarcoma of the bone: A case report of high resistance to chemotherapy and a survey of the literature. Sarcoma 2010;2010:431627. http://dx.doi.org/10.1155/2010/431627

6. Tomimaru Y, Nagano H, Marubashi S, et al. Sclerosing epithelioid fibrosarcoma of the liver infiltrating the inferior vena cava. World J Gastroenterol 2009;15:4204-8. http://dx.doi.org/10.3748/wig.15.4204
7. Massier A, Scheithauer BW, Taylor HC, et al. Sclerosing epithelioid fibrosarcoma of the pituitary. Endocr Pathol 2007;18:233-8. http://dx.doi.org/10.1007/s12022-007-9010-2

8. Frattini JC, Sosa JA, Carmack S, et al. Sclerosing epithelioid fibrosarcoma of the cecum: A radiationassociated tumour in a previously unreported site. Arch Pathol Lab Med 2007;131:1825-8.

9. Bai S, Jhala N, Adsay NV, et al. Sclerosing epithelioid fibrosarcoma of the pancreas. Ann Diagn Pathol 2013;17:214-6. http://dx.doi.org/10.1016/j.anndiagpath.2011.06.006

10. Leisibach $P$, Weder $W$, Soltermann A, et al. Primary sclerosing epithelioid fibrosarcoma of the lung in a patient with Lynch syndrome. Lung 2012;190:691-5. http://dx.doi.org/10.1007/s00408-012-9401-0

11. Arya $M$, Garcia-Montes F, Patel HR, et al. A rare tumour in the pelvis presenting with lower urinary symptoms : Sclerosing epithelioid fibrosarcoma. Eur I Surg Oncol 2001;27:121-2. http://dx.doi. org/10.1053/eiso.2000.1023

12. Elkins CT, Wakely PE. Sclerosing epithelioid fibrosarcoma of the oral cavity. Head Neck Pathol 201 1;5:42831. http://dx.doi.org/10.1007/s12105-011-0277-8

13. Watanabe K, Suzuki T. Epithelioid fibrosarcoma of the ovary. Virchows Arch 2004;445:410-3. http:// dx.doi.org/10.1007/s00428-004-1068-3

14. Decroisette C, Melloni B, Moldovan D, et al. Pleural metastases of sclerosing epithelioid fibrosarcoma. Rev Pneumol Clin 2006;62:179-82. http://dx.doi.org/10.1016/S0761-8417(06)75435-9

Correspondence: Dr. Michael D. Bell, Department of Surgery, Division of Urology, McGill University Health Centre, Montreal, QC, Canada; michael.bell@mail.mcgill.ca 